\title{
Analysis of Water Shortage Solution Based on Gray Prediction
}

\author{
Xinqiao Zheng
}

School of North China Electric Power University, Energy Power and Mechanical Engineering, Baoding, Hebei Province, China.

1766937377@qq.com

Keywords: Water Scarcity, Forecasting Model, the Gray Correlation Analysis Method.

\begin{abstract}
With the increase of population and the change of climate, the problem of water shortage is becoming more and more serious. The global water scarcity has been a critical challenge for human beings in twenty-first Century. Our model takes Beijing that is serious shortage of water for example. We use the gray correlation analysis method to analyze the reasons for the lack of water in Beijing and find that agricultural water and industrial water account for the major proportion. Further, prediction models of Task 1 are used to predict the change trend of each factor in the next 15 years. The fitting effect of prediction curves is very good, and it shows that prediction methods are reasonable and accurate. According to these changing trends, the influence of citizens' life in the future is expected.
\end{abstract}

\section{Introduction}

Water resources are the most important resources in human production and life, but nowadays, the shortage of water resources has become a universal concern ever since. With the increase of population and the development of economy, the demand for water resources is increasing, which leads to the increasingly prominent contradiction between supply and demand.

Sea water on the surface of the earth accounts for about $97.5 \%$ of the hydrosphere, and fresh water for only $2.5 \%$ of the total reserves. However, lakes, rivers and shallow underground freshwater resources that are relatively easy to develop and use, account for merely $0.34 \%$ of total freshwater reserves. Humans require water resources for industrial, agricultural, residential and environmental purposes. According to survey statistics, the world's annual water consumption is basically in accordance with 3\% 5\% growth. Water use has been growing at twice the rate of population over the last century. At the same time, up to $1 / 4$ of the world's water supply cannot be safely used because of the pollution.

The reasons for the global water shortage are as follows:

\section{Internal factors}

- Fresh water resources are originally limited.

- Distribution of fresh water resources is extremely uneven.

- It is much more difficult to find an ideal substitute for water.

\section{External factors}

- Industrial, agricultural and other living water consumption has continued to expand.

- The destruction of the ecological environment and global warming cause the reduction of water resources.

- Natural water resources are polluted by waste water, which causes the decrease of water quality.

- Waste of water resources is caused by improper use of management.

\subsection{Analysis of Water Resources Supply}

\subsubsection{Utilizable Precipitation Analysis}

Utilizable precipitation can be used as an important component of water resources supply in an area, so it is very important to predict its accuracy. Reference to the meteorological data in this area, we study the specific changes in the amount of utilizable precipitation in this region. Given that the forecast results should have practical reference value, this article only carries on the short-term forecast to it. 
Time series combination forecasting method based on mean generating function is used in the precipitation forecasting model.

\subsection{Entry Water Analysis}

According to the hypothesis, the entry water quantity and the utilizable precipitation have the same characteristics, which can be characterized by mean and discrete values of a certain period. So here we take the same prediction model as the former.

\subsection{Regression Forecasting Model of Renewable Water}

The recovery and utilization of water resources is the direction of the world water resources strategy, which should have a significant change over time. There are many methods to fit and predict the time series of this type, including regression model, moving average model, neural network, gray model and so on. The regression forecasting model only needs a small amount of data to predict the behavior of an unknown system. There may not be much data in some area, so we use this method to predict the supply of water.

However, due to the different level of economic and scientific and technological level, there are different changes in the short-term renewable water in different regions. So here we use variable to represent the renewable water in the region:

\subsection{Water Transfer Project Prediction Model}

$$
Y=f(x)
$$

It is one of the ways to solve the uneven distribution of water resources. It is assumed that there is no new water transfer project in the local area, so the water transfer capability of this area is limited in the short term. This ability is constantly increasing when the water transfer capability is not completely formed, and is not reached the maximum. When the maximum value is reached, it will no longer change, whose change is related to the progress of the implementation of the water transfer project.

So we need to study this process according to the specific planning of this area. Again this is done as follows:

$$
\mathrm{y}=\left\{\begin{array}{l}
f(t), y \leq C_{\max } \\
C_{\max }, \text { others }
\end{array}\right.
$$

\subsection{Groundwater Exploitation Analysis}

Groundwater is a region's last use of water resources. When the total amount of other water resources cannot meet the demand, it is needed to exploit groundwater resources to fill the gap of the water demand, which will lead to a drop in the water table.

\subsection{Analysis of Water Resources Demand}

For the change in the short term of four kinds of water resources is influenced by many factors, this paper temporarily ignore internal mechanism, and simply analyze the change law of the data, and then continue to analyze the influence of each factor on them in detail. In this paper, we will use the gray prediction model to forecast the four kinds of demand. We need to analyze the influencing factors in detail according to the specific situation and then calculate the demand in the case of possible errors in the demand.

\subsection{Domestic water}

Living water meets the basic needs of people's lives. Population growth, urban environmental constructions are the main driving factors to promote the rapid increase in life with water express. In this paper, we mainly consider the total population of the region and the annual per capita water consumption, and the specific relationship between water consumption and water consumption is as follows:

$$
Y_{1}=P_{O}^{*} \text { Ave }
$$

Where represents the total population of the region, represents annual per capita water consumption. Po Ave

Therefore, the prediction and control of the water consumption in a region can be realized by controlling the total population and the annual per capita water consumption.

In this paper, the classical Logistic model is used to forecast the population. Grey forecasting model is used to forecast the per capita water consumption of residents. In an ideal situation, the annual per capita water consumption should be maintained at a value that can satisfy the people's 
normal life. That is to say: it can't be too big or too small. Otherwise, it is a need to take appropriate measures to control.

\subsection{Industrial Water}

Industrial water consumption of ten thousand yuan output value refers to the amount of water used by the industrial enterprises to produce the final products or to provide the unit labor service activities in a certain period of time, which can better reflect the economic benefits of the water sector for each. So we can use industrial output value of ten thousand yuan output value and the annual industrial production value of the local area to predict the industrial water demand. Select the data of several cities in recent ten years to make the change trend chart. We find that the change trend chart is approximate to the negative exponential function curve.

\subsection{Agricultural Water}

Agricultural water mainly includes two parts of irrigation water and Forestry Animal Husbandry Fishery Water, in which the irrigation water accounts for more than $90 \%$ of agricultural water, and it is related to water-saving technology, irrigation area and crop structure, etc. With the development of urbanization and the improvement of water saving technology, the planting area of crops and the effective irrigation area are reduced, which causes the agricultural water use quantity to reduce unceasingly. Its changing trend is similar to that of industrial water.

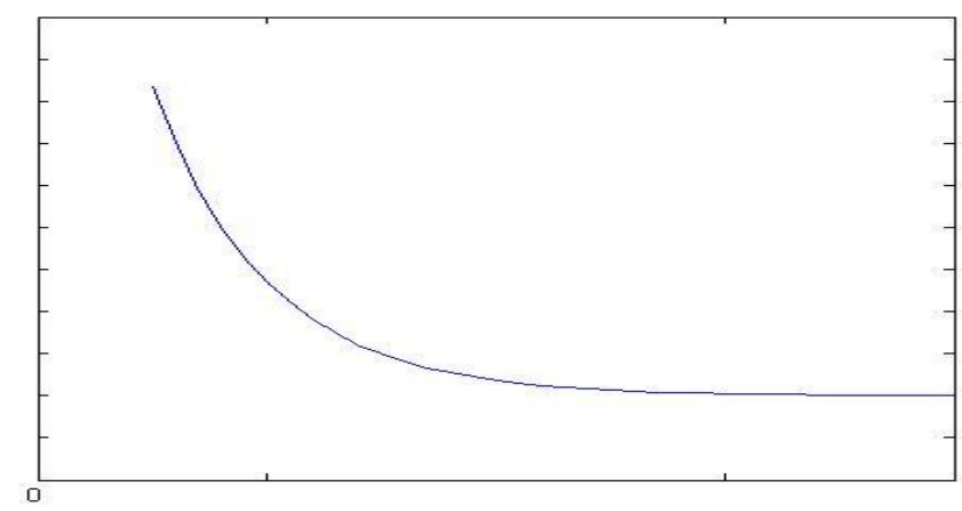

Fig. 1 The negative exponential function curve

\section{Conclusion}

To sum up, a region's water supply and demand are determined by the corresponding factors. Life, industry, agriculture and the environment as the four major sectors of water, and its changes directly affect the size of the total water. The total water consumption can be obtained by analyzing the water consumption of each department.

In the same way, the total water supply can be obtained by analyzing and calculating the available water quantity of each part. By comparing the total amount of water supply and water demand in the region to determine the water shortage in the region, it further measures the ability of the region to provide clean water resources to meet the needs of the local population. Because of the detailed analysis of the influence factors of water supply and demand, the total amount of water supply and water demand are relatively accurate, so the model is reasonable.

\section{References}

[1]. Shou-kui Si, Xi-jing Sun. Mathematical Modeling [M]. National Defend Industry Press , September 2014.

[2]. Beijing water resources bulletin.

[3]. Beijing statistical yearbook 2015.

[4]. Report on the relationship between water resources and urban development in Tianjin (final draft). 